\title{
Synergetic Depolymerization of Aspen CEL by Pyranose 2-Oxidase and Lignin-degrading Peroxidases
}

\author{
Fangfang Wang, ${ }^{\mathrm{a}, *}$ Feng Huang, ${ }^{\mathrm{b}}$ and Mingqiang $\mathrm{Ai}^{\mathrm{c}}$ \\ Three enzymatic treatments were compared for the depolymerization of \\ cellulolytic enzyme lignin (CEL) from aspen; these systems used pyranose \\ 2 -oxidase and lignin-degrading peroxidases. The "P" system was mainly \\ composed of pyranose 2-oxidase, lignin peroxidase (LiP), and manganese \\ peroxidase (MnP). Catalase and vitamin $\mathrm{C}$ were added to the $\mathrm{P}$ system to \\ decompose $\mathrm{H}_{2} \mathrm{O}_{2}$ to control the $\mathrm{H}_{2} \mathrm{O}_{2}$ concentration. The system to which \\ catalase was added was called the "C" system. The system to which \\ catalase and vitamin $\mathrm{C}$ were added together was called the " $\mathrm{V}$ " system. \\ Ultraviolet-visible (UV-Vis) spectra of supernatants after aspen CEL \\ treatment by the $\mathrm{P}, \mathrm{C}$, or $\mathrm{V}$ system was used to monitor the amount of \\ water-soluble lignin fragments that were generated, which increased with \\ system treatment time. A gel permeation chromatography (GPC) analysis \\ showed that after $12 \mathrm{~h}$ of system treatment, the molecular weight $\left(M_{w}\right)$ of \\ CEL was efficiently lowered; the maximum $M_{w}$ reduction of aspen CEL \\ was $20 \%$ when compared to the blank and control runs. The residual \\ enzymatic activity of the supernatant after the CEL treatment by the P, C, \\ or $\mathrm{V}$ system indicated that $\mathrm{MnP}$ and LiP activity for lignin degradation was \\ dependent upon the $\mathrm{H}_{2} \mathrm{O}_{2}$ concentration. Therefore, it is advised that $\mathrm{MnP}$ \\ and LiP be applied separately for effective lignin degradation.
}

Keywords: Synergetic degradation; Lignin; Pyranose 2-oxidase; Lignin peroxidase; Manganese peroxidase

Contact information: a: State Key Laboratory of Bio-Based Material and Green Papermaking, Qilu University of Technology (Shandong Academy of Sciences), Jinan, 250353, China; b: Microbial Technology Institute, Shandong University, Qingdao, 266237,China; c: School of Biological Sciences, Jining Medical University, Rizhao, 276826, China; *Corresponding author: wff_928@126.com

\section{INTRODUCTION}

Lignin is a heterogeneous biopolymer that is the most abundant aromatic material on Earth. It accounts for nearly $30 \%$ of the total organic carbon found in nature. Lignin is one of the few renewable feedstocks for the production of aromatic chemicals (Rahimi et al. 2014). However, the highly complex structure of lignin, in addition to its highly recalcitrant constitution that physically protects cellulose and hemicelluloses from hydrolysis degradation in the plant cell wall, has so far hampered many efforts to increase its application value (Bruijnincx and Weckhuysen 2014). Lignin depolymerization is an important process to efficiently utilize lignin for high-value products; such processes could provide a source of low-molecular-mass aromatic feedstocks that are suitable for downstream processing into bio-based materials in pharmaceutical and chemical industry (Ragauskas et al. 2014; Rahimi et al. 2014). Lignin bio-depolymerization can provide a green, mild, and energy-saving route for the production of low-molecular-mass aromatic feedstocks.

Lignin is degraded by a narrower range of microbes when compared to other major biopolymers found in nature. White rot fungi degrade lignin more rapidly and extensively 
than other microbial groups (Camarero et al. 2014; Rouches et al. 2016). Meanwhile, the structural features of lignin require the biosystems responsible for initial depolymerization to be extracellular, nonspecific, and non-hydrolytic (Kirk and Farrell 1987). It is yet to be discovered the extracellular enzymes that are related to lignin biodegradation that are secreted by the white rot fungi, and contain lignin peroxidase (LiP), manganese peroxidase $(\mathrm{MnP})$, laccase, $\mathrm{H}_{2} \mathrm{O}_{2}$-generating enzyme, and lignin fragment radicals reductase. In addition, some small molecular mass mediators, e.g., veratryl alcohol, oxalate, $\mathrm{Mn}^{3+}-\mathrm{Mn}^{2+}$ and/or $\mathrm{Fe}^{3+}-\mathrm{Fe}^{2+}$, are also involved in the lignin degradation because the size of the secreted enzymes are too large to diffuse into the fiber walls (Janusz et al. 2017). In addition to lignin degradation, the lignin extracellular degrading enzyme discovered also can degrade many persistent organic pollutants to remove the environmental pollution caused by them.

Lignin peroxidase is able to depolymerize lignin when $\mathrm{H}_{2} \mathrm{O}_{2}$ is present (Odier et al. 1988). When the way of $\mathrm{H}_{2} \mathrm{O}_{2}$ supply changed from the interval supply to the continuous supply via a peristaltic pump or glucose oxidase, lignin degradation was observed (Hammel and Moen 1991; Wariishi et al. 1991; Hammel et al. 1993). The actions of glucose oxidase and pyranose 2-oxidase for reducing quinoid intermediates improved the depolymerization of kraft (sulfate) lignins by laccase (Ai et al. 2014). Thus, in vitro, the extracellular biodepolymerization of lignin is an oxidative process controlled by the reductive reaction and/or the supply of $\mathrm{H}_{2} \mathrm{O}_{2}$.

Pyranose 2-oxidase can also generate $\mathrm{H}_{2} \mathrm{O}_{2}$ while reducing quinoid groups. In this research there was an attempt to achieve synergistic effects in the degradation of cellulolytic enzyme lignin (CEL), which was obtained from aspen, by pyranose 2-oxidase, lignin peroxidase (LiP), and manganese peroxidase $(\mathrm{MnP})$. To better understand the factors affecting decomposition, three systems were compared. The first system was mainly composed of pyranose 2-oxidase, lignin peroxidase (LiP), and manganese peroxidase $(\mathrm{MnP})$. Catalase and vitamin $\mathrm{C}$ were added to the first system to control the $\mathrm{H}_{2} \mathrm{O}_{2}$ concentration. The system that catalase was added into the first system formed the second system. The system that catalase and vitamin $\mathrm{C}$ were all added into the first system was the third system.

\section{EXPERIMENTAL}

\section{Materials}

All solvents used in this study were analytical reagent grade and used as purchased without further purification unless otherwise stated. The tetrahydrofuran (THF) used was chromatographic grade. The 1,4-dioxane, THF, pyridine, and acetic anhydrate were distilled prior to being used. Catalase, veratryl alcohol, and 2,6-dimethoxyphenol $(2,6-$ DMP) were purchased from Sigma (Sigma-Aldrich, Shanghai, China). Other chemicals were purchased from Sinopharm Chemical Reagent Co., Ltd. (Shanghai, China). Cellulase was provided by Novozymes (Beijing, China); it contained $202 \mathrm{IU} / \mathrm{g}$ xylanase, $308 \mathrm{IU} / \mathrm{g} \beta$ D-glucosidase, $0.407 \mathrm{IU} / \mathrm{g}$ cellobiohydrolase, $99 \mathrm{IU} / \mathrm{g}$ endoglucosidase, and $608 \mathrm{IU} / \mathrm{g}$ filter paper unit (FPU) activity.

\section{Lignin}

Cellulolytic enzyme lignin (CEL) was isolated from aspen wood according to the method of Zhang et al. (2010). The weighted-average molecular weight $(M w)$ of the CEL obtained was approximately $16,000 \mathrm{~g} / \mathrm{mol}$. 
Enzymes

Pyranose oxidase was obtained from Irpex lacteus dft-1. Its purification was completed in accordance to the method of Ai et al. (2014). The LiP and MnP were obtained from Phanerochaete chrysosporium ME446. The cultivation and purification of these enzymes was performed in accordance to the method reported by Tien and Kirk (1988), with the exception that $3 \mathrm{mM}$ veratryl alcohol was used instead of $40 \mathrm{mM}$. Nine proteins detected from the Mono-Q column had absorbance at $409 \mathrm{~nm}$. According to the elution sequence and Kirk's naming, there was no fifth protein (H5), and there were H1, H2, H3, $\mathrm{H} 4, \mathrm{H} 6, \mathrm{H} 7, \mathrm{H} 8, \mathrm{H} 9$, and H10. The protein designated H1, H2, H6, H7, H8, H9, and H10 had LiP activity. $\mathrm{H} 3$ and $\mathrm{H} 4$ had $\mathrm{MnP}$ activity. The mixed $\mathrm{MnP}(\mathrm{H} 3$ and $\mathrm{H} 4)$ and the mixed $\mathrm{LiP}(\mathrm{H} 1, \mathrm{H} 2, \mathrm{H} 6, \mathrm{H} 7, \mathrm{H} 8$, and H10) were used in the experiments of this study.

\section{Treatment of CEL by pyranose 2-oxidase and lignin degrading peroxidases}

The CEL (10 mg) was added to a 50-mL sterilized conical centrifuge tube. The system designated as the $\mathrm{P}$ system contained the following items added to $10 \mathrm{~mL}$ of a 4.5 pH buffered solution (20 mM sodium succinate): 3 IU LiP, 4 IU MnP, 0.3 IU pyranose 2oxidase, $0.15 \mathrm{IU}$ inactivated catalase, $4 \mu \mathrm{mol}$ veratryl alcohol, $5 \mu \mathrm{mol} \mathrm{Mn^{2+ }}, 500 \mu \mathrm{mol}$ lactate acid, and $500 \mu \mathrm{mol}$ glucose. The system designated as the $\mathrm{C}$ system had the same components of the $\mathrm{P}$ system except that activated catalase was used in place of the inactivated catalase. The system designated as the $\mathrm{V}$ system contained the same components as the $\mathrm{C}$ system except that the $\mathrm{V}$ system contained $2 \mu \mathrm{mol}$ of vitamin $\mathrm{C}$. Pyranose 2-oxidase was inactivated in the control experiments, which had the same components as the $\mathrm{P}$ system. All of the enzymes were inactivated in the blank experiments, which had the same components as the $\mathrm{P}$ system. The veratryl alcohol, $\mathrm{Mn}^{2+}$, lactate acid, and glucose were filtered and sterilized. The $4.5 \mathrm{pH}$ buffer of sodium succinate was sterilized in an autoclave. There were three replicates for every experiment.

A 50-mL conical centrifuge tube was sealed with a silicone plug into which a 6$\mathrm{mm}$ diameter syringe needle was inserted as the oxygen outlet, and a 3.2-mm male luer straight joint was inserted as the oxygen inlet (Fig. 1). A syringe needle needle-head and the Pagoda interface of the inserted male luer straight joint were facing towards the inside of the centrifuge tube. The Pagoda interface of the male luer straight joint was connected with a 9-cm-long and 3-mm inner diameter silicone tube. The free end of the silicone tube was connected to a $10-\mu \mathrm{L}$ suction head whose cusp was submerged $1.8 \mathrm{~cm}$ into the liquid of the conical centrifuge tube. The other end of the male luer straight joint was connected a 20-cm-long and 3-mm inner diameter silicone tube. The silicone tube was connected to the 20-outlet gas discharge whose main inlet was connected to the oxygen cylinder with an 8-mm inner diameter silicon tube. All of the silicon tubes and the gas discharge were sterilized in an autoclave.

These 50-mL conical centrifuge tubes with the silicone plug and connected tubes were placed in a shaking water bath at $40{ }^{\circ} \mathrm{C}$ at an oscillation rate of $120 \mathrm{rpm}$. The rate of oxygen introduced into the tube was adjusted to one bubble per second. One tube of the blank, control, P system, C system, and V system were removed from the shaking bath at $3,6,12$, and $24 \mathrm{~h}$ intervals. The remained outlets of the gas discharge were sealed after the samples were removed. 


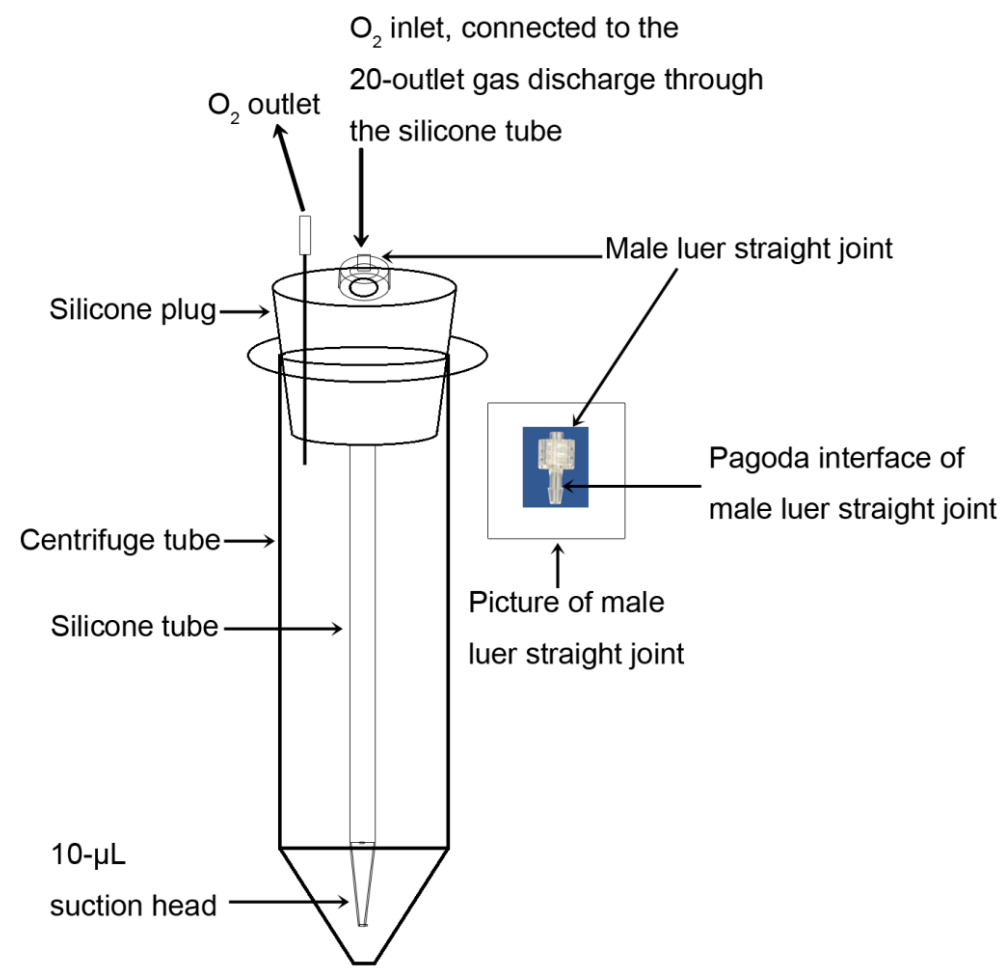

Fig. 1. Schematic of the CEL degradation device used in this study

The sample that was removed from the shaking water bath was centrifuged at $10,000 \mathrm{rpm}$ at $4{ }^{\circ} \mathrm{C}$. The resulting supernatant was transferred using a pipette into a $15-\mathrm{mL}$ centrifuge tube. Then, the supernatant was kept at $4{ }^{\circ} \mathrm{C}$ for residual enzyme activity determinations and ultraviolet-visible (UV-Vis) scanning. The solid lignin was washed three times with double distilled water; afterwards, the washed solids were dried under vacuum.

\section{Methods}

Determination of residual enzyme activity

The LiP activity was measured spectrophotometrically during the oxidation of veratryl alcohol to veratraldehyde in the presence of $\mathrm{H}_{2} \mathrm{O}_{2}$ in a $2.5 \mathrm{pH}$ sodium tartrate buffer $(250 \mathrm{mM})$ at $310 \mathrm{~nm}$ wavelength $\left(\varepsilon_{310 \mathrm{~nm}}=9,300 \mathrm{M}^{-1} \mathrm{~cm}^{-1}\right)$ (Haq et al. 2016). The MnP assay was based on the oxidation of 2,6-dimethoxyphenol to 3,3',5,5'-tetramethoxydiphenoquinone in the presence $\mathrm{Mn}^{2+}$ and $\mathrm{H}_{2} \mathrm{O}_{2}$ in a $4.5 \mathrm{pH}$ sodium lactate buffer (100 $\mathrm{mM})$ at $469 \mathrm{~nm}$ wavelength $\left(\varepsilon 469 \mathrm{~nm}=49,600 \mathrm{M}^{-1} \mathrm{~cm}^{-1}\right)(\mathrm{Ng}$ et al. 2015$)$. Pyranose 2-oxidase activity was determined by monitoring the formation of $\mathrm{H}_{2} \mathrm{O}_{2}$ with a peroxidase-catalyzed chromogenic reaction with 2,2'-azinobis(3-ethylbenzthiazoline-6-sulfonic acid) (ABTS) at $420 \mathrm{~nm}$ wavelength $\left(\varepsilon 420 \mathrm{~nm}=43,200 \mathrm{M}^{-1} \mathrm{~cm}^{-1}\right)$ (Ai et al. 2014). Catalase activity was measured spectrophotometrically by monitoring the $\mathrm{H}_{2} \mathrm{O}_{2}$ breakdown at $240 \mathrm{~nm}$ wavelength $\left(\varepsilon_{420 \mathrm{~nm}}=43.6 \mathrm{M}^{-1} \mathrm{~cm}^{-1}\right)($ Ogunlana et al. 2012$)$.

\section{$U V$-Vis spectroscopy}

The UV-Vis absorption spectra of the centrifuged supernatants were recorded over the range of 190 to $700 \mathrm{~nm}$ (at a $1 \mathrm{~nm}$ resolution) using a spectrophotometer (Agilent 8453; 
Agilent Technologies, Santa Clara, CA, USA). The rectangular quartz cuvette used in the spectrophotometer had a path length of $1 \mathrm{~cm}$.

\section{Gel permeation chromatography $(G P C)$}

The dried solid lignin was dissolved in $250 \mu \mathrm{L}$ of distilled pyridine and $250 \mu \mathrm{L}$ of distilled acetic anhydride for $72 \mathrm{~h}$ under darkness. The lignin acetylation was performed with slight shaking at room temperature. The acetylated lignin was precipitated in $7 \mathrm{~mL}$ diethyl ether and washed three times with diethyl ether. The acetylated lignin was finally dried and kept under vacuum at $30^{\circ} \mathrm{C}$.

The molecular weight distributions of the treated CELs were measured using a Waters 1515-2414 gel permeation chromatograph (Waters, Milford, MA, USA) with a Styragel ${ }^{\circledR}$ HT THF column. The dried and acetylated lignin was dissolved in tetrahydrofuran $(4 \mathrm{mg} / \mathrm{mL})$ overnight. The solution was filtered through a $0.22-\mu \mathrm{m}$ polytetrafluoroethylene(PTFE) membrane to avoid plugging the GPC column. A volume of $50 \mu \mathrm{L}$ of the filtrate was injected. The temperature of the column was $39{ }^{\circ} \mathrm{C}$. Tetrahydrofuran was used as the mobile phase with a flow rate of $1 \mathrm{~mL} / \mathrm{min}$. A differential refractometer (RI; Waters, Milford, MA, USA) was used as the detector at the end of the column. Polystyrene standards were used to generate a weighted-average molecular weight calibration curve.

\section{RESULTS AND DISCUSSION}

\section{UV-Vis of Supernatant Generated from the CEL Treated by Pyranose 2- Oxidase and Lignin Degrading Peroxidases}

The resolutions obtained from the recorded UV spectra $(190 \mathrm{~nm}$ to $240 \mathrm{~nm})$ of the supernatants were too low to obtain discernible differences among the enzymatic degradation treatments. The absorbance level obtained from the recorded visible spectra (400 $\mathrm{nm}$ to $700 \mathrm{~nm}$ ) of the supernatants were too similar to obtain discernible differences among the enzymatic degradation treatments. The near ultraviolet spectra regions $(240 \mathrm{~nm}$ to $400 \mathrm{~nm}$ ) for the various degradation treatments are shown in Fig. 2. All spectra had a strong absorbance band centered at $280 \mathrm{~nm}$. The absorbance at $280 \mathrm{~nm}$ of the supernatant from the control in which lignin was only treated by peroxidases; these spectra peaks were higher than those of the blank (no active enzymes present). The absorbance at $280 \mathrm{~nm}$ of the supernatants obtained after lignin treatment by the P, C, and V enzymatic systems were all higher than the supernatant of the control. The strong absorbance centered at $280 \mathrm{~nm}$ is assigned to the non-conjugated phenolic structures of lignin (Xu et al. 2006; Bahl et al. 2014). The amount of protein added in all systems was the same. Thus, the differences observed in the absorbance around $280 \mathrm{~nm}$ were attributed to new phenolic structures being generated during the enzymatic depolymerization of the CEL by the various systems. This indicated that pyranose 2-oxidase and peroxidases can synergistic-ally cleave the $\beta-\mathrm{O}-4$ linkages in lignin to create more unconjugated phenolics in the solubilized lignin. All supernatants from the three enzymatic systems, except for the $\mathrm{C}$ system at $3 \mathrm{~h}$ treatment, had a shoulder peak around $310 \mathrm{~nm}$ (Figs. 2A through 2D). This shoulder peak may associate with veratraldehyde, which evolves from the oxidation of veratryl alcohol by LiP in the lignin treatment system. Likewise, this peak could be attributed to some lignin degradation products, such as $p$-coumaric, vanillic, ferulic, and sinapinic acid (Herrera and Luque de Castro 2005; Waliszewski et al. 2007; Lu et al. 2017; Soltani et al. 2018). 

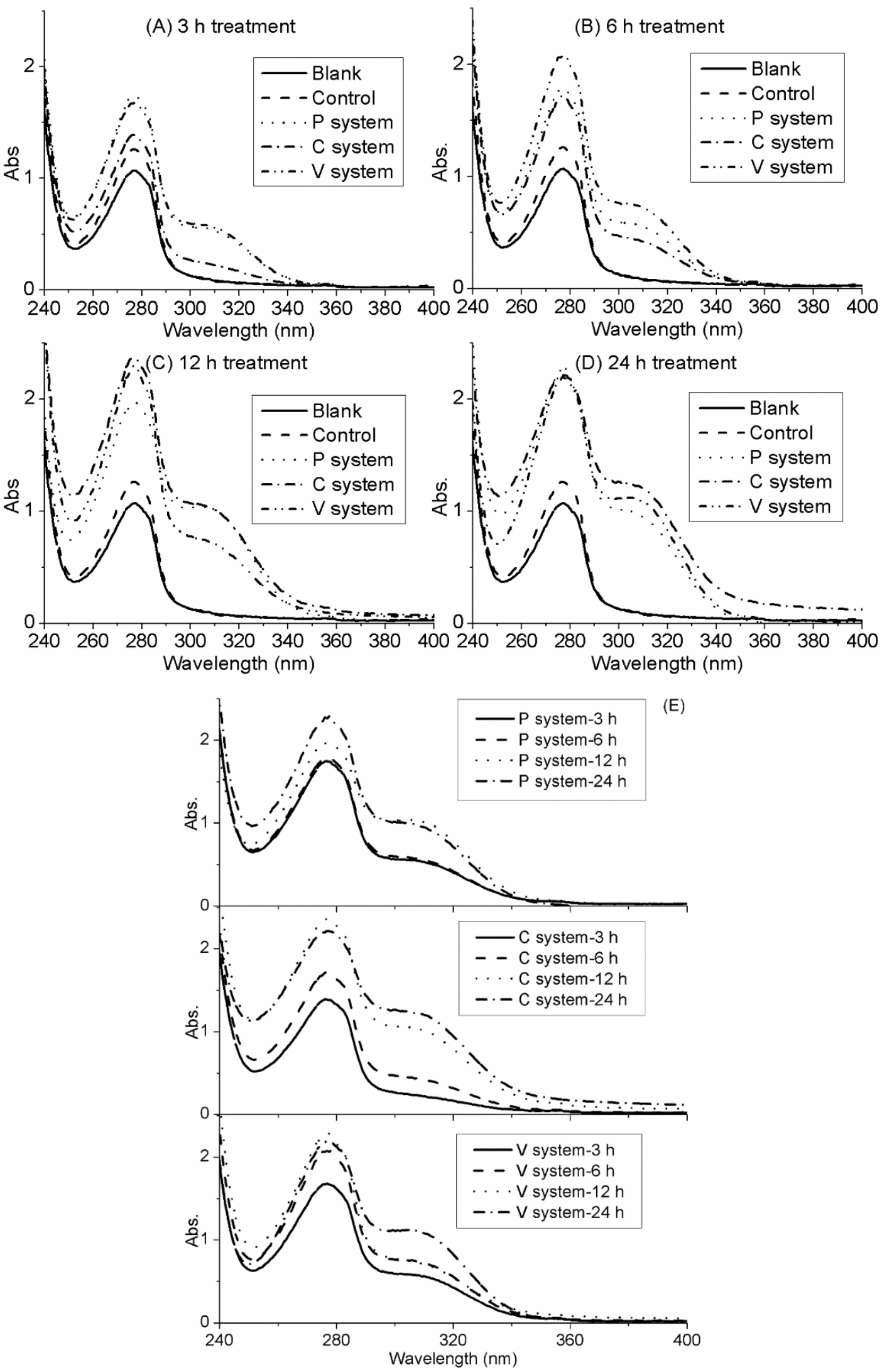

Fig. 2. Near ultraviolet spectra of CEL supernatants after treatment by pyranose 2-oxidase-lignin degrading peroxidases systems 
After 3 and $6 \mathrm{~h}$ of enzymatic degradation treatment, the absorbance at 280 and 310 $\mathrm{nm}$ of the supernatants from the $\mathrm{P}$ and $\mathrm{V}$ system were higher than the $\mathrm{C}$ system (

FigA and 2B). After 12 and $24 \mathrm{~h}$ of enzymatic degradation treatment, the absorbance at 280 and $310 \mathrm{~nm}$ of the supernatants from the $\mathrm{P}$ and $\mathrm{V}$ system was lower than the $\mathrm{C}$ system (

FigC and 2D). The absorbance at $280 \mathrm{~nm}$ of the supernatant from the $\mathrm{P}$ system increased with increasing treatment time, as well as the absorbance at $310 \mathrm{~nm}$ until $12 \mathrm{~h}$ (Fig. 2E). For the $\mathrm{C}$ and $\mathrm{V}$ systems, the absorbance at $280 \mathrm{~nm}$ of the supernatants increased over the $12 \mathrm{~h}$ of treatment, whereas the absorbance at $310 \mathrm{~nm}$ continued to increase during the $24 \mathrm{~h}$ of treatment (Fig. 2E). Hence, with increased enzymatic treatment time, the amount of the water-soluble lignin fragments produced from the depolymerization of CEL by the $\mathrm{P}, \mathrm{C}$, or $\mathrm{V}$ system also increased.

\section{Molecular Weight of CEL After Pyranose Oxidase-lignin Degrading Peroxidases Treatments}

Figures 3 and 4 indicate that the $M_{n}$ and $M_{w}$ of the CEL in the blank and control treatments were unchanged as the treatment time increased. The $M_{n}$ and $M_{w}$ of the CEL from the control were lower than the blank. This observation suggested that the control treatment depolymerized CEL. A previous investigation reported that lignin peroxidase can oxidize $\mathrm{Mn}^{2+}$ to $\mathrm{Mn}^{3+}$ in the presence of veratryl alcohol, oxygen, and lactic acid (Popp et al. 1990). The generating $\mathrm{Mn}^{3+}$ could oxidize phenolic lignin structures, which degraded the CEL. This oxidative degradation reaction could explain the decrease of the $M_{n}$ and $M_{w}$ values of the CEL in the control versus the blank treatment.

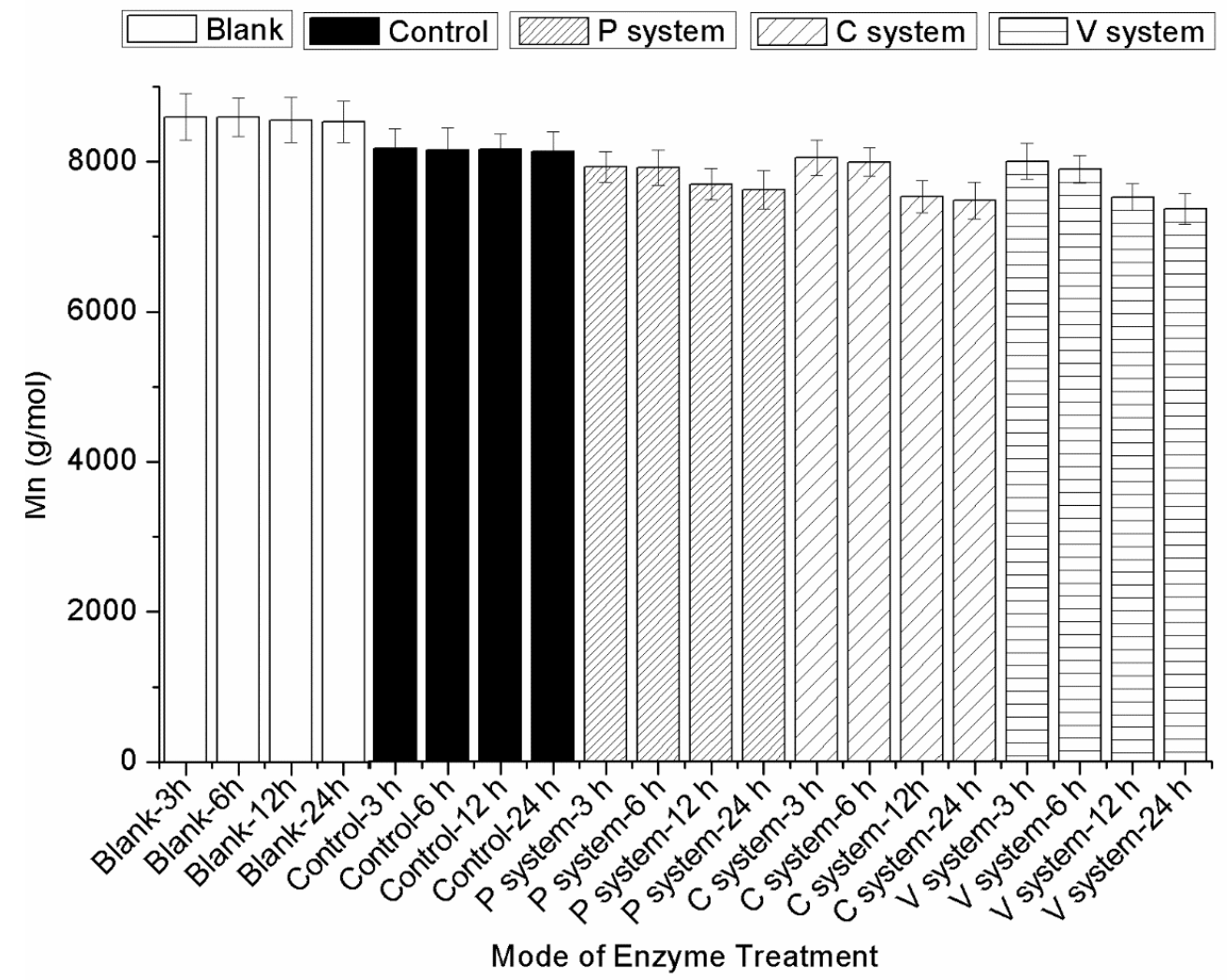

Fig. 3. Number-average molecular weight $\left(M_{n}\right)$ of the $C E L$ after various pyranose 2-oxidase-lignin degrading peroxidases treatments 


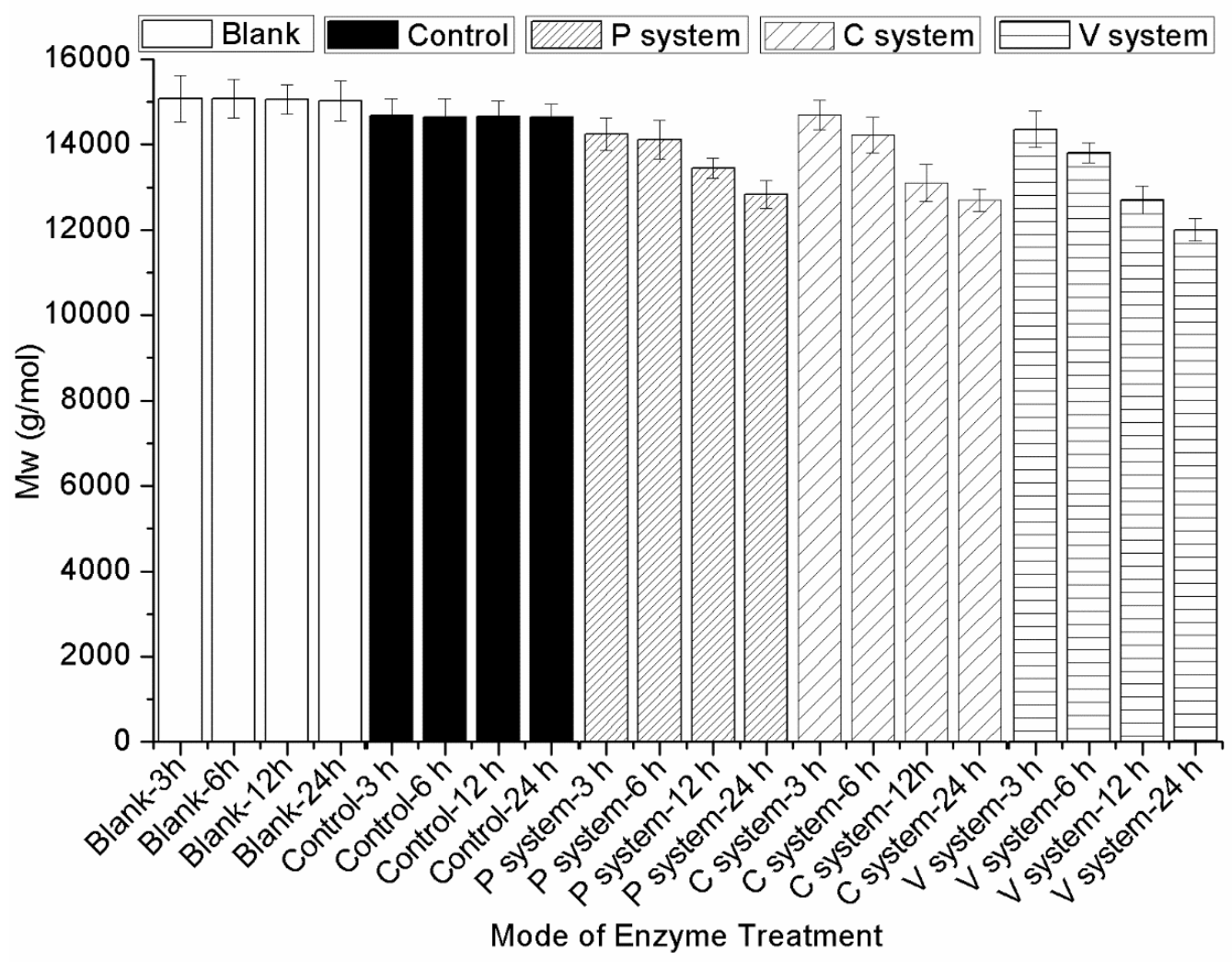

Fig. 4. Weighted-average molecular weight $\left(M_{w}\right)$ of the CEL after various pyranose 2-oxidaselignin degrading peroxidases treatments

In Figs. 3 and 4 the histograms became shorter within P, C, and V groups, which indicates an enzymatic treatment effect increasing with increasing lengths of time. When compared to the corresponding control, the P, C, or V system caused the $M_{n}$ and $M_{w}$ values to decrease with increasing treatment time. The reduction rate of the $M_{n}$ and $M_{w}$ values was fastest after $12 \mathrm{~h}$ (Figs. 3 and 4). After 3 and $6 \mathrm{~h}$ of enzymatic treatment, the $M_{w}$ and $M_{n}$ values of the CEL treated by the $\mathrm{C}$ system were slightly higher than the CEL treated by the $\mathrm{P}$ or V systems (Figs. 3 and 4). Consequently, the amount of the water-soluble lignin fragments produced from the $\mathrm{C}$ system was lower than those from the $\mathrm{P}$ or $\mathrm{V}$ systems; this observation was consistent with the observed UV-Vis absorption of the supernatants after P, C, or V treatments (Fig. 2). The $M_{w}$ and $M_{n}$ of the CEL after the V system for $24 \mathrm{~h}$ decreased $20 \%$ and $14 \%$, respectively, when compared to the blank. After 12 and $24 \mathrm{~h}$ of treatment, the $M_{w}$ and $M_{n}$ of the CEL by the V system were lower than that of the C system, and the $M_{w}$ and $M_{n}$ of the CEL obtained from the $\mathrm{C}$ system was lower than the $\mathrm{P}$ system (Figs. 3 and 4). This observation indicated that after $12 \mathrm{~h}$ of enzymatic degradation treatment, the addition of catalase to the $\mathrm{C}$ system enhanced the synergetic depolymerization of CEL by lignin peroxidases and pyranose 2-oxidase. Vitamin C addition to the $\mathrm{V}$ system further enhanced this effect. It has been previously reported that vitamin $\mathrm{C}$ can contribute to the degradation of a synthetic lignin polymer by $P$. chrysosporium (Hong et al. 2017). 


\section{Residual Enzyme Activities After Pyranose 2-Oxidase Lignin-degrading Peroxidases Treatments}

The residual enzyme activities in the supernatants after the different pyranose 2oxidase-lignin peroxidases system treatments are shown in Fig. 5. The blank treatment exhibited no residual enzymatic activities (i.e., LiP, MnP, pyranose 2-oxidase, and catalase) (Fig. 5). This observation was consistent with the fact that all of the enzymes used in the blank treatment were deactivated. In comparison to the initial enzyme activity added to the control (i.e., $0.3 \mathrm{IU} / \mathrm{mL} \mathrm{LiP}$ and $0.4 \mathrm{IU} / \mathrm{mL} \mathrm{MnP}$ ), there was lower residual LiP activity and higher residual $\mathrm{MnP}$ activity after the treatment. During the course of the control treatment, the residual LiP activity remained almost unchanged, whereas the residual $\mathrm{MnP}$ activity gradually decreased (Figs. 5A and 5B).
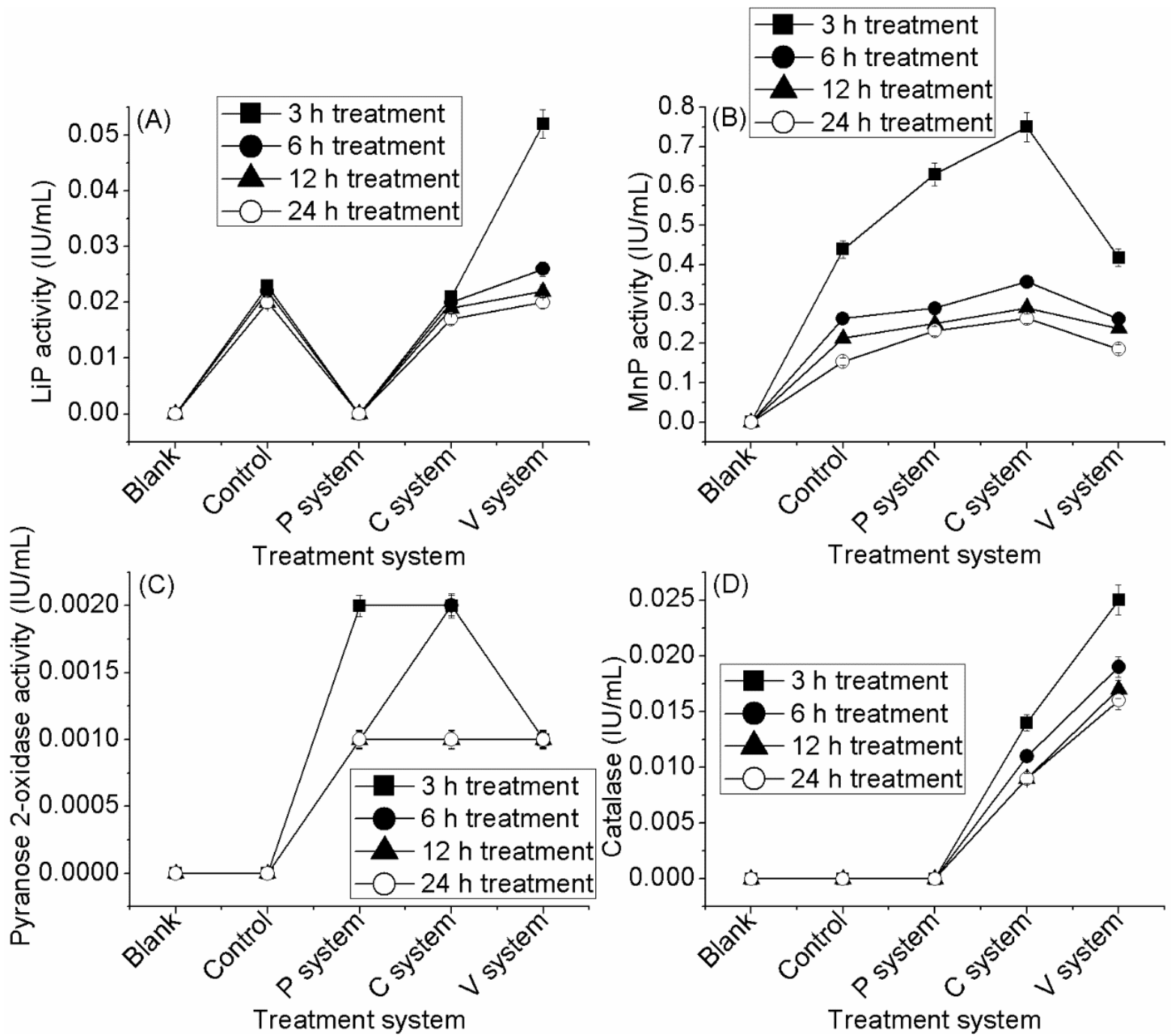

Fig. 5. Residual enzyme activities of pyranose 2-oxidase lignin-degrading peroxidases, and catalase for $\mathrm{P}, \mathrm{C}$, and $\mathrm{V}$ systems versus blank and control treatments 
For the $\mathrm{P}$ system, the residual LiP activity was undetected during the entire treatment time (Fig. 5A). However, there was higher residual MnP activity and lower residual pyranose 2-oxidase activity when compared to the initial enzymatic conditions of the $\mathrm{P}$ system (Figs. 5B and 5C). The residual MnP activity in the $\mathrm{P}$ system was higher than that of the control at the same treatment time (Fig. 5B). In the $\mathrm{C}$ system, the residual LiP activity was lower, the residual $\mathrm{MnP}$ was higher, the residual pyranose 2-oxidase was lower, and the residual catalase was higher than the initial conditions at $3 \mathrm{~h}, 6 \mathrm{~h}, 12 \mathrm{~h}$, and $24 \mathrm{~h}$ (Figs. 5A to 5D). Similarly, the residual MnP and catalase activities in the $\mathrm{C}$ system decreased as the treatment time increased. There was higher residual LiP activity in the $\mathrm{V}$ system versus the control, the $\mathrm{P}$ system, and the $\mathrm{C}$ system. In addition, the $\mathrm{V}$ system had higher MnP, lower pyranose 2-oxidase, and higher catalase activities after $3 \mathrm{~h}, 6 \mathrm{~h}, 12 \mathrm{~h}$, and 24 treatment times versus the initial conditions. The residual $\mathrm{MnP}$ and catalase activities gradually decreased with the V system as the treatment time increased.

Pyranose 2-oxidase produced excess hydrogen peroxide, which inactivated the LiP (Wong 2009). Hence, there was no LiP activity in the P system (Fig. 5A). However, the $M_{w}$ value of the CEL decreased with the P system after $24 \mathrm{~h}$ of treatment. This observation indicated that the CEL depolymerization was not caused by the action of LiP. In this case, CEL depolymerization was mainly attributed to the effect of MnP. The dose of pyranose 2-oxidase added to the $\mathrm{P}$ system was appropriate for $\mathrm{MnP}$ (Fig. 5B) because the activity of $\mathrm{MnP}$ in the $\mathrm{P}$ system after $3 \mathrm{~h}$ treatment was higher than the initial amount. The effect of active pyranose 2-oxidase on $\mathrm{MnP}$ is same as $\mathrm{MnP}$ with glucose oxidase (Ansari et al. 2016, 2017). In the $\mathrm{C}$ system, LiP and MnP of $3 \mathrm{~h}$ treatment was $0.021 \mathrm{IU} / \mathrm{mL}$ and 0.75 $\mathrm{IU} / \mathrm{mL}$. When compared to the initial added LiP and MnP activity, catalase restored LiP activity to $7 \%$ after $3 \mathrm{~h}$ and made the $\mathrm{MnP}$ activity to increase 1.87 times. It indicated that the inactivation of LiP was partially mitigated by the catalytic decomposition of $\mathrm{H}_{2} \mathrm{O}_{2}$ by added catalase and the activity of $\mathrm{MnP}$ in the $\mathrm{C}$ system was further enhanced (Fig. 5B). Thus, the $M_{w}$ of the CEL after the C system treatment for 12 and $24 \mathrm{~h}$ was lower than that of the $\mathrm{P}$ system treatment. In the $\mathrm{V}$ system, LiP activity increased $17 \%$ after $3 \mathrm{~h}$ treatment. Catalase and vitamin $\mathrm{C}$ allowed more of the LiP to remain in its active form, although the activity of $\mathrm{MnP}$ after $3 \mathrm{~h}$ treatment reverted to the same level as the control. The $M_{w}$ of the CEL after the V system treatment for 12 and $24 \mathrm{~h}$ decreased even further. 


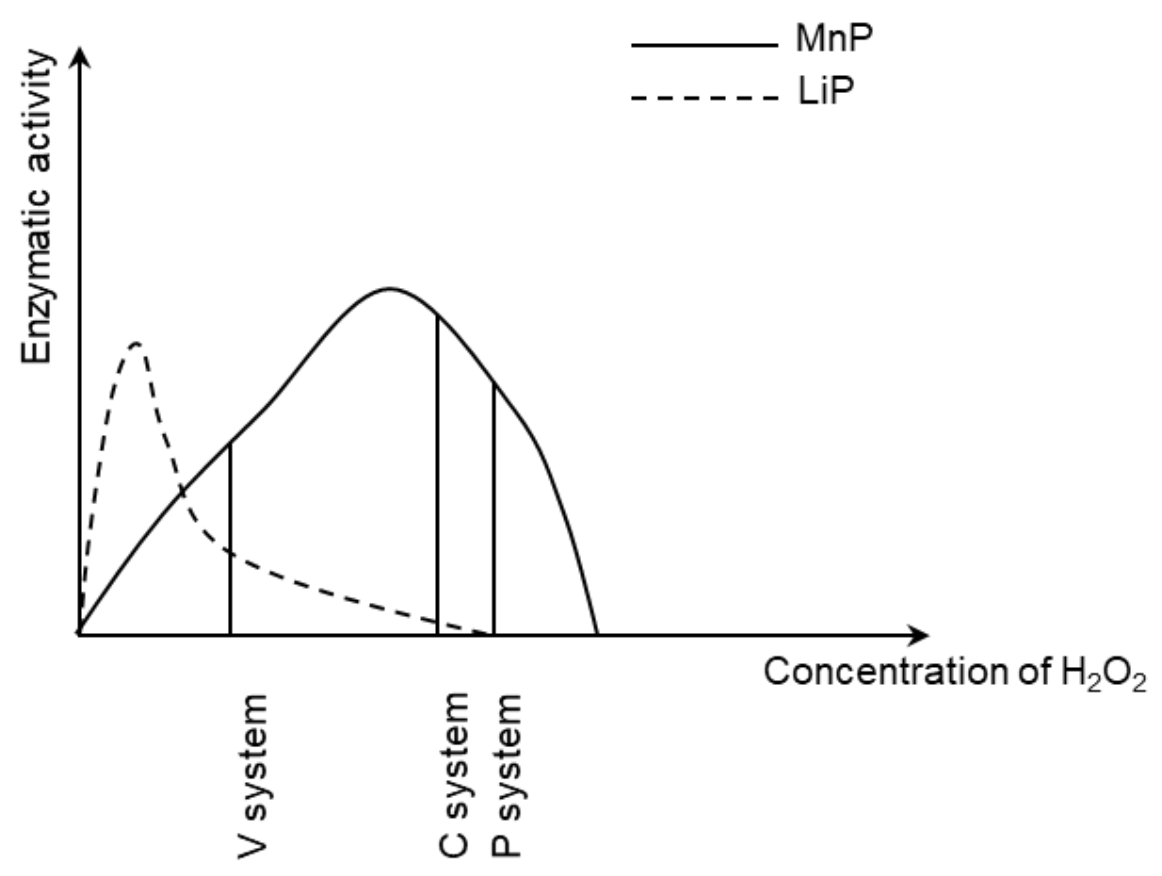

Fig. 6. Schematic diagram of presumed activity changes to LiP and MnP with the concentration of $\mathrm{H}_{2} \mathrm{O}_{2}$

Catalase can catalyze $\mathrm{H}_{2} \mathrm{O}_{2}$ decomposition and decrease its concentration in the system as it is generated by pyranose 2-oxidase. In this experiment the lower $\mathrm{H}_{2} \mathrm{O}_{2}$ concentration in the $\mathrm{C}$ system versus the $\mathrm{P}$ system enhanced the activities of $\mathrm{LiP}$ and $\mathrm{MnP}$ for the $\mathrm{C}$ system (Fig. 5). Vitamin $\mathrm{C}$ converted $\mathrm{H}_{2} \mathrm{O}_{2}$ to water and oxygen, which reduced the concentration of $\mathrm{H}_{2} \mathrm{O}_{2}$ in the $\mathrm{V}$ system. Hence, high LiP activity was more efficiently retained, but the activity of $\mathrm{MnP}$ was reduced (Fig. 5). This may have been attributable to the fact that the optimum amount of $\mathrm{H}_{2} \mathrm{O}_{2}$ produced from pyranose 2-oxidase that is needed for $\mathrm{LiP}$ and $\mathrm{MnP}$ to depolymerize lignin and for the peroxidases to remain active may have been appreciably different from one another (Fig. 6). Consequently, to construct an efficient system of lignin depolymerization, when pyranose 2-oxidase is used as the generator of $\mathrm{H}_{2} \mathrm{O}_{2}$, it is advised that $\mathrm{LiP}$ and $\mathrm{MnP}$ should be separately applied to lignin depolymerization. The ratio of $\mathrm{MnP}$ or $\mathrm{LiP}$ to pyranose 2-oxidase for lignin depolymerization needs to be further studied to determine the optimum value. In addition, the activities of $\mathrm{MnP}$ and $\mathrm{LiP}$ in relation to the concentration of $\mathrm{H}_{2} \mathrm{O}_{2}$ need to be investigated to determine the most favorable conditions.

\section{CONCLUSIONS}

1. Pyranose 2-oxidase and lignin-degrading peroxidases efficiently depolymerized aspen CEL during $24 \mathrm{~h}$ of treatment.

2. Compared to the initial added enzymatic activity, catalase restored LiP activity to $7 \%$ and $\mathrm{MnP}$ activity increased by 1.87 times after $3 \mathrm{~h}$ treatment in the $\mathrm{C}$ system. 
3. Compared to the initial added enzymatic activity, catalase and vitamin $\mathrm{C}$ restored LiP activity to $17 \%$ and had no capacity to activate $\mathrm{MnP}$ after $3 \mathrm{~h}$ treatment in the $\mathrm{V}$ system.

4. The optimum amount of $\mathrm{H}_{2} \mathrm{O}_{2}$ produced from pyranose 2-oxidase that is needed for $\mathrm{LiP}$ and $\mathrm{MnP}$ to depolymerize lignin was appreciably different from one another. To construct an efficient system of lignin depolymerization, when pyranose 2-oxidase is used, it is advised that $\mathrm{LiP}$ and $\mathrm{MnP}$ should be separately applied to lignin depolymerization.

\section{ACKNOWLEDGEMENTS}

This work was supported by the Director's Fund of the State Key Laboratory of Bio-Based Materials and Green Papermaking at Qilu University of Technology (Grant No. 030803138612) and was helped with providing the Irpex lacteus dft-1 and Phanerochaete chrysosporium ME446 by the Microbial Technology Institute of Shandong University.

\section{REFERENCES CITED}

Ai, M.-Q., Wang, F.-F., Zhang, Y.-Z., and Huang, F. (2014). "Purification of pyranose oxidase from the white rot fungus Irpex lacteus and its cooperation with laccase in lignin degradation," Process Biochem. 49(12), 2191-2198. DOI: 10.1016/j.procbio.2014.10.001

Ansari, Z., Karimi, A., Ebrahimi, S., and Emami, E. (2016). "Improvement in ligninolytic activity of Phanerochaete chrysosporium cultures by glucose oxidase," Biochem. Eng. J. 105(Part B), 332-338. DOI: 10.1016/j.bej.2015.10.007

Ansari, Z., Karimi, A., Sedghi, S., Razzaghi, M., and Ebrahimi, S. (2017). "Glucose oxidase effect on treatment of textile effluent containing reactive azo dyes by Phanerochaete chrysosporium," J. Chem. Technol. Biot. 92(7), 1721-1726. DOI: 10.1002/jctb.5170

Bahl, K., Swanson, N., Pugh, C., and Jana, S. C. (2014). "Polybutadiene-gpolypentafluorostyrene as a coupling agent for lignin-filled rubber compounds," Polymer 55(26), 6754-6763. DOI: 10.1016/j.polymer.2014.11.008

Bruijnincx, P. C., and Weckhuysen, B. M. (2014). "Biomass conversion: Lignin up for break-down," Nat. Chem. 6(12), 1035-1036. DOI: 10.1038/nchem.2120

Camarero, S., Martínez, M. J., and Martínez, A. T. (2014). "Understanding lignin biodegradation for the improved utilization of plant biomass in modern biorefineries," Biofuel. Bioprod. Bior. 8(5), 615-625. DOI: 10.1002/bbb.1467

Hammel, K. E., Jensen, Jr., K. A., Mozuch, M. D., Landucci, L. L., Tien, M., and Pease, E. A. (1993). "Ligninolysis by a purified lignin peroxidase," J. Biol. Chem. 268(17), 12274-12281.

Hammel, K. E., and Moen, M. A. (1991). "Depolymerization of a synthetic lignin in vitro by lignin peroxidase," Enzyme Microb. Tech. 13(1), 15-18. DOI: 10.1016/01410229(91)90182-A

Haq, I., Kumar, S., Kumari, V., Singh, S. K., and Raj, A. (2016). "Evaluation of bioremediation potentiality of ligninolytic Serratia liquefaciens for detoxification of 
pulp and paper mill effluent," J. Hazard. Mater. 305, 190-199. DOI:

10.1016/j.jhazmat.2015.11.046

Herrera, M. C., and Luque de Castro, M. D. (2005). "Ultrasound-assisted extraction of phenolic compounds from strawberries prior to liquid chromatographic separation and photodiode array ultraviolet detection," J. Chromatogr. A 1100(1), 1-7. DOI: 10.1016/j.chroma.2005.09.021

Hong, C.-Y., Ryu, S.-H., Jeong, H., Lee, S.-S., Kim, M., and Choi, I.-G. (2017). "Phanerochaete chrysosporium multienzyme catabolic system for in vivo modification of synthetic lignin to succinic acid," ACS Chem. Biol. 12(7), 1749-1759. DOI: 10.1021/acschembio.7b00046

Janusz, G., Pawlik, A., Sulej, J., Świderska-Burek, U., Jarosz-Wilkołazka, A., and Paszczyński, A. (2017). "Lignin degradation: Microorganisms, enzymes involved, genomes analysis and evolution," FEMS Microbiol. Rev. 41(6), 941-962. DOI: 10.1093/femsre/fux049

Kirk, T. K., and Farrell, R. L. (1987). "Enzymatic 'combustion': The microbial degradation of lignin," Annu. Rev. Microbiol. 41(1), 465-501. DOI: 10.1146/annurev.mi.41.100187.002341

Lu, Y., Memon, A., Fuerst, P., Kizonas, A., Morris, C., and Luthria, D. (2017). "Changes in the phenolic acids composition during pancake preparation: Whole and refined grain flour and processed food classification by UV and NIR spectral fingerprinting method-Proof of concept," J. Food Compos. Anal. 60, 10-16. DOI: 10.1016/j.jfca.2017.03.001

Ng, I. S., Xu, F., Zhang, X., and Ye, C. (2015). "Enzymatic exploration of catalase from a nanoparticle producing and biodecolorizing algae Shewanella xiamenensis BC01," Bioresource Technol. 184, 429-435. DOI: 10.1016/j.biortech.2014.09.079

Odier, E., Mozuch, M. D., Kalyanaraman, B., and Kirk, T. K. (1988). "Ligninasemediated phenoxy radical formation and polymerization unaffected by cellobiose: Quinone oxidoreductase," Biochimie 70(6), 847-852. DOI: 10.1016/03009084(88)90117-4

Ogunlana, O. O., Ogunlana, O. E., Ntube, C. A., Olagunju, J. A., and Akindahunsi, A. A. (2012). "Phytochemical screening and in vivo antioxidant activity of ethanolic extract of Caesalpinia bondus (L.) Roxb," Global Research Journal of Pharmaceutical Sciences 1(1), 1-5.

Popp, J. L., Kalyanaraman, B., and Kirk, T. K. (1990). "Lignin peroxidase oxidation of manganese (II) in the presence of veratryl alcohol, malonic or oxalic acid, and oxygen," Biochem. 29(46), 10475-10480. DOI: 10.1021/bi00498a008

Ragauskas, A. J., Beckham, G. T., Biddy, M. J., Chandra, R., Chen, F., Davis, M. F., Davison, B. H., Dixon, R. A., Gilna, P., and Keller, M. (2014). "Lignin valorization: Improving lignin processing in the biorefinery," Science 344(6185), 709-720. DOI: 10.1126/science. 1246843

Rahimi, A., Ulbrich, A., Coon, J. J., and Stahl, S. S. (2014). "Formic-acid-induced depolymerization of oxidized lignin to aromatics," Nature 515, 249-252. DOI: 10.1038/nature13867

Rouches, E., Herpoël-Gimbert, I., Steyer, J. P., and Carrere, H. (2016). "Improvement of anaerobic degradation by white-rot fungi pretreatment of lignocellulosic biomass: A review," Renew. Sust. Energ. Rev. 59, 179-198. DOI: 10.1016/j.rser.2015.12.317

Soltani, R., Shahvar, A., Dinari, M., and Saraji, M. (2018). "Environmentally-friendly and ultrasonic-assisted preparation of two-dimensional ultrathin $\mathrm{Ni} / \mathrm{Co}-\mathrm{NO}_{3}$ layered 
double hydroxide nanosheet for micro solid-phase extraction of phenolic acids from fruit juices," Ultrason. Sonochem. 40(Part A), 395-401. DOI: 10.1016/j.ultsonch.2017.07.031

Tien, M., and Kirk, T. K. (1988). "Lignin peroxidase of Phanerochaete chrysosporium," Method. Enzymol. 161, 238-249. DOI: 10.1016/0076-6879(88)61025-1

Waliszewski, K. N., Pardio, V. T., and Ovando, S. L. (2007). "A simple and rapid HPLC technique for vanillin determination in alcohol extract," Food Chem. 101(3), 10591062. DOI: 10.1016/j.foodchem.2006.03.004

Wariishi, H., Valli, K., and Gold, M. H. (1991). "In vitro depolymerization of lignin by manganese peroxidase of Phanerochaete chrysosporium," Biochem. Bioph. Res. Co. 176(1), 269-275. DOI: 10.1016/0006-291X(91)90919-X

Wong, D. W. S. (2009). "Structure and action mechanism of ligninolytic enzymes," Appl. Biochem. Biotech. 157(2), 174-209. DOI: 10.1007/s12010-008-8279-Z

Xu, F., Sun, J.-X., Sun, R., Fowler, P., and Baird, M. S. (2006). "Comparative study of organosolv lignins from wheat straw," Ind. Crop. Prod. 23(2), 180-193. DOI: 10.1016/j.indcrop.2005.05.008

Zhang, A., Lu, F., Sun, R.-C., and Ralph, J. (2010). "Isolation of cellulolytic enzyme lignin from wood preswollen/dissolved in dimethyl sulfoxide $/ N$-methylimidazole," $J$. Agr. Food Chem. 58(6), 3446-3450. DOI: 10.1021/jf903998d

Article submitted: November 21, 2018; Peer review completed: February 4, 2019;

Revised version received and accepted: February 22, 2109; Published: March 8, 2019.

DOI: $10.15376 /$ biores. 14.2.3481-3494 